\title{
SEMINÁRIO LINGUAGEM VISUAL E EDUCAÇÃO BÁSICA
}

\author{
Esequiel Rodrigues Oliveira ${ }^{1}$ \\ Maria Ignez Rocha David ${ }^{2}$ \\ Maria Ruth Machado Fellows ${ }^{3}$ \\ Soraya Barcellos Izar ${ }^{4}$ \\ CAP-UERJ
}

\section{RESUMO:}

Não somos preparados para receber de forma consciente as imagens que atuam na nossa formação moral e intelectual. Nunca houve da parte da educação formal uma preocupação com a leitura de imagens da mesma forma como sempre existiu com a leitura das letras. 0 pensamento visual raras vezes é levado em consideração pela escola e valorizado como parceiro da escrita na construção do conhecimento. Na realidade, a escola dá pouca importância à formação nesta linguagem no processo de aprendizagem do aluno. Portanto, desenvolver estudos que contribuam para o fomento de uma reflexão em torno da formação instrumental e crítica em linguagem visual como parte integrante da formação escolar básica e, conseqüentemente, da demanda de inserção na sociedade contemporânea, é tarefa fundamental de todos aqueles envolvidos no processo Educacional, qualquer que seja o nível de atuação.

PALAVRAS-Chave: linguagem visual, educação básica, formação docente

\begin{abstract}
:
We are not prepared for consciously receive images that contribute to our moral and intellectual formation. Formal education has never dedicated the same attention to the reading of images as the dedicated to the reading of letters. Visual thought is hardly ever taken in account by school and never regarded as a partner of writing towards the construction of knowledge. In fact, school does not draw much attention to the formation in visual language. Therefore, it is a fundamental task for all of those involved in the educational process to carry out studies that may contribute for the development of a reflection on an instrumental and critic formation on visual language as a part of basic school education, and consequently as a demand for insertion in contemporary society.
\end{abstract}

KEY-WORDS: visual language, basic education, teacher formation 
e-Mosaicos - Revista Multidisciplinar de Ensino, Pesquisa, Extensão e Cultura do Instituto de Aplicação Fernando Rodrigues da Silveira (CAp-UERJ)

ANO 1 - V. 1 - N. 1 - JUNHO 2012 - ISSN: 2316-9303

\section{INTRODUÇÃO}

A imagem sempre exerceu um papel narrativo, descritivo e persuasivo na sociedade. Os sonhos, por exemplo, têm seu enredo construído através de imagens. A experiência onírica intrigou egípcios, gregos e mais recentemente Freud que, a partir da interpretação dessas experiências, revolucionou a ciência, estabelecendo um marco na história do pensamento.

Retrocedendo consideravelmente no tempo, chegando à Pré-História, podemos avaliar a importância atribuída à produção das imagens, até mesmo para a sobrevivência daqueles grupos humanos. De volta aos tempos atuais, temos as novas tecnologias que criam imagens cada vez mais sofisticadas, vulgarizam seu uso, ampliam de forma inimaginável sua difusão, tornando-as parte integrante e indispensável na construção do conhecimento.

Se fizermos um passeio mais demorado pela História da Humanidade, vamos identificar a presença constante de imagens nos vários campos do saber. Todas as áreas da atividade humana delas se serviram em algum momento, para atingir objetivos específicos. Isso nos remete à crença num processo intuitivo, ou seja, natural de leitura de imagens.

Entretanto, o uso dessas imagens não se dá de maneira natural; sua produção é pensada, escolhas são realizadas, códigos são estabelecidos com seus símbolos, signos e sinais, o que significa dizer que existe uma linguagem visual que deve ser aprendida para que ocorra a comunicação.

Mas linguagem visual não é apenas um sistema de signos que serve de meio de comunicação entre indivíduos e pode ser percebido pelos órgãos dos sentidos; é também um meio de apreender conceitos, de ampliar e de produzir conhecimento do mundo físico e cultural, e um instrumento de formação de consciência. No entanto, o público receptor continua utilizando critérios intuitivos de recepção e visualização dos textos visuais, de leitura e análise desses discursos, consumindo desordenadamente e de forma acrítica as imagens que lhes são apresentadas, o que revela a permanência da crença no processo natural quando a questão é imagem.

Hoje, no mundo imagético em que vivemos, essa crença não mais se justifica. Portanto, desenvolver estudos que contribuam para o fomento de uma reflexão em torno da formação instrumental e crítica em linguagem visual como parte integrante da formação escolar básica e, consequentemente, da demanda de inserção na sociedade contemporânea, é tarefa fundamental de todos aqueles envolvidos no processo Educacional, qualquer que seja o nível de atuação.

\section{O Projeto Leden}

Não somos preparados para receber de forma consciente as imagens que atuam na nossa formação moral e intelectual. Nunca houve da parte da educação formal uma preocupação com a leitura de imagens da mesma forma como sempre existiu com a leitura das letras. $O$ pensamento visual raras vezes é levado em consideração pela escola e valorizado como parceiro da escrita na construção do conhecimento. Na realidade, a escola dá pouca importância à formação nessa linguagem no processo de aprendizagem do aluno.

A atual estruturação do ensino escolar, no que diz respeito à linguagem visual, ou seja, a linguagem que tem a imagem como suporte, não atende às necessidades da 
e-Mosaicos - Revista Multidisciplinar de Ensino, Pesquisa, Extensão e Cultura do Instituto de Aplicação Fernando Rodrigues da Silveira (CAp-UERJ) ANO 1 - V. 1 - N. 1 - JUNHO 2012 - ISSN: 2316-9303

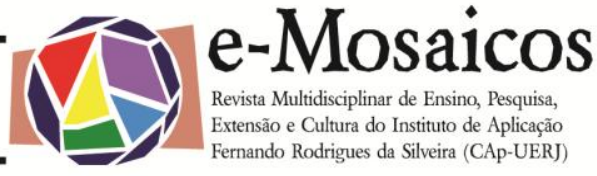

sociedade contemporânea. 0 ensino das artes plásticas, rebatizada de artes visuais para ampliar seu campo de ação, não encontra espaço, nem profissionais capacitados para instrumentalizar a leitura crítica de imagens, e tampouco sua produção, numa perspectiva transdisciplinar. Na realidade, não existem diretrizes metodológicas que trabalhem de forma sistematizada a imagem, e conseqüentemente a linguagem visual, relacionada a aspectos sócio-cognitivo, cultural e político-ideológico; isto é, a educação formal não reconhece a imagem e suas implicações na construção do conhecimento.

Acreditamos que se a aprendizagem da leitura e expressão do texto visual fosse concomitante à aprendizagem da leitura e expressão do texto verbal, teríamos, no futuro, cidadãos mais críticos e mais capazes de se relacionar com o universo que nos rodeia. São recorrentes os diagnósticos de fracasso escolar relacionado à dificuldade na aquisição da linguagem escrita formal; e esporádicos os relatos de sucesso quando do trabalho concomitante das duas linguagens, não devido a uma eficiência duvidosa, mas à ausência e/ou a um subaproveitamento de recursos visuais e audiovisuais nos procedimentos didáticos pedagógicos e nos processos cognitivos por parte do professor.

Nesse sentido, o Projeto LEDEN - Laboratório de Ensino de Desenho e Linguagem Visual na Escola - Ensino, Pesquisa e Extensão propõe um espaço na educação brasileira para o trabalho com a linguagem visual, tanto na Educação Básica como na formação docente. Constituindo-se num ambiente propício a práticas pedagógicas, atividades de extensão e de pesquisa, realiza uma busca que passa pelo mapeamento de ações pedagógicas, pela socialização dessas ações, pela instrumentalização através das novas tecnologias e pela construção teórica, ainda insipiente, referentes à linguagem visual.

Hoje, o Projeto LEDEN desenvolve atividades focalizando três eixos, a saber: a linguagem visual como área de conhecimento na Educação Básica; a formação docente em linguagem visual; e investigações interdisciplinares: a linguagem visual em outras áreas de conhecimento, contempladas respectivamente pelos seguintes projetos de pesquisa e extensão: CAp Identidade: espaço e memória virtual; Linguagem Visual Instrumental; e Imagem Matemática. Nessas atividades estão envolvidos professores e estudantes dos Ensinos Fundamental e Médio do Instituto de Aplicação Fernando Rodrigues da Silveira - CAp-UERJ e professores da Educação Básica das Redes Públicas Estadual e Municipais do Estado do Rio de Janeiro.

O Projeto LEDEN se sustenta na concepção de Desenho como uma expressão da linguagem visual, entendida não apenas como o sistema de signos que servem de meio de comunicação entre indivíduos e podem ser percebidos pelos órgãos dos sentidos, mas também como instrumento de formação de consciência, que designa objetos, extrai - abstraindo - propriedades e cria categorias (ALMEIDA, 1994; DONDIS, 2000; FERRARA, 1986; FERREIRA， 1999; LURIA, 1987). Nesse sentido, o desenho é visto não como uma técnica de reprodução de imagens ou de construção passo a passo de formas geométricas, mas como meio de compreender símbolos conceituais geométricos, de ampliar o conhecimento do mundo físico e cultural e de produzir realidade.

Diferente da concepção de aprendizagem da formação escolar básica que remonta ao século XIX, na qual se defendia a reprodução de uma forma repetidas vezes como procedimento eficaz para a fixação da 
e-Mosaicos - Revista Multidisciplinar de Ensino, Pesquisa, Extensão e Cultura do Instituto de Aplicação Fernando Rodrigues da Silveira (CAp-UERJ) ANO 1 - V. 1 - N. 1 - JUNHO 2012 - ISSN: 2316-9303

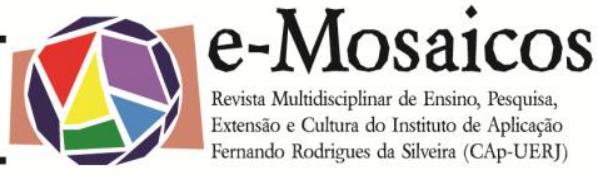

referida forma que poderia estar relacionada a qualquer área do conhecimento, o que se pretende com esse projeto é construir uma aprendizagem baseada na experiência cotidiana, isto é, observando a realidade, pois, segundo Derdyk: "Desenhar não é copiar figuras, formas, não é simplesmente proporção e escala... são tentativas de aproximação com o mundo. Desenhar é conhecer, é apropriar-se." (1994, p.24)

Representar um objeto é conhecê-lo. É analisar suas características formais, seu significado cultural, suas relações espaciais e semânticas em determinado contexto. É também um meio de desenvolver uma ideia, de melhor elaborá-la, de submetê-la à própria crítica, de avançar inicialmente na criação e de posteriormente compartilhar a informação.

Para que se obtenha a melhor expressão visual do objeto a ser representado, há que se desenvolver habilidades e competências em linguagem visual; e, para isso, dominar um conjunto de conceitos relacionados à sistematização da representação da nossa experiência visual, associando-o ao contexto sócio-cultural. É necessário "dominar a linguagem visual", posto que: "a linguagem visual é a base da criação no desenho", conclui Wong (2001, p.41).

Este projeto se propõe, portanto, a investigar diversos aspectos da formação em linguagem visual no contexto da prática do ensino de desenho, dentre os quais, podemos destacar, as possibilidades tecnológicas, a perspectiva transdisciplinar e as dimensões crítica e criativa da formação do aluno na Escola Básica. Entendemos, no entanto, que tal formação se processa de forma articulada com outras linguagens verbais e não-verbais - nas diversas áreas de conhecimento. Por isso, defendemos que a habilidade de leitura e expressão em lin- guagem visual está - também - na base da formação crítica do cidadão, proporcionando, desse modo, uma participação social mais qualificada.

Assim, o projeto tem, entre outras finalidades, a atividade de extensão que focaliza a formação docente continuada, formação que se realiza através de cursos de atualização, de orientação à pesquisa em nível de Iniciação Científica no Ensino Médio, de estímulo à reflexão (epistemológica, teóricoconceitual ou metodológica), da criação de materiais didáticos e da organização de eventos. E como primeiro evento, previsto pelo LEDEN desde sua criação, o I Seminário de Pesquisa e Práticas Pedagógicas Linguagem Visual e Educação Básica vem responder às demandas identificadas em pesquisa de campo junto a professores da Rede Pública Estadual do Rio de Janeiro, demandas essas que acreditamos ser também de grande parte dos docentes de todo o país - e não só das redes públicas - que atuam na Educação Básica.

\section{I I Seminário de Pesquisa e Práticas Pedagógicas - Linguagem VISUAL E EDUCAÇão Básica}

O I Seminário de Pesquisa e Práticas Pedagógicas - Linguagem Visual e Educação Básica constitui uma das etapas da iniciativa do LEDEN de subsidiar a discussão em torno do uso da imagem pelos docentes que atuam na Educação Básica. O Evento tem como objetivo organizar um fórum de intercâmbio de experiências pedagógicas, bem como de divulgação da produção acadêmica sobre o tema, a partir do olhar das diferentes áreas de conhecimento, pretendendo promover um ambiente favorável ao surgimento de uma nova perspectiva curricular para a Educação Básica e, conseqüentemente, para a 
e-Mosaicos - Revista Multidisciplinar de Ensino, Pesquisa, Extensão e Cultura do Instituto de Aplicação Fernando Rodrigues da Silveira (CAp-UERJ) ANO 1 - V. 1 - N. 1 - JUNHO 2012 - ISSN: 2316-9303

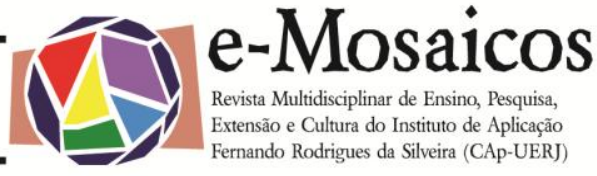

formação docente, na qual a imagem esteja entre os planos de expressão da linguagem.

A estrutura de troca é a base de toda e qualquer reflexão. Acreditando nisso, decidimos por um formato de organização do Seminário em plenárias, de maneira a potencializar o compartilhamento das idéias. As sessões de apresentação de trabalhos, todas realizadas em um auditório, permitem que todos os participantes tenham acesso às mesmas informações, gerando assim um acúmulo de idéias e, por conseguinte, certa movimentação das mesmas.

Cabe ressaltar que essa troca, essa movimentação, não se inicia nas sessões plenárias, mas na preparação dos trabalhos a serem apresentados. E na apresentação desses trabalhos sobre linguagem visual é exigida a utilização de imagens; ou seja, é preciso falar de imagem através de imagens. Essa exigência promove encontros, trocas e reflexões anteriores àqueles esperados durante a realização do Seminário e que, de certa forma, antecipam algumas respostas esperadas por nós em relação às demandas sobre a utilização de novas tecnologias. O LEDEN, disponibilizando seu espaço, sua equipe e seus recursos tecnológicos, visa dar suporte aos docentes que, porventura, não dispõem dos recursos necessários, quaisquer que sejam eles, para a elaboração de seu trabalho.

Sendo assim, pretendemos que não só - Seminário em si, mas também sua preparação contribuam para a formação docente, o que vem contemplar um dos objetivos do Projeto LEDEN, na medida em que estamos buscando estabelecer relações entre a comunicação visual, a tecnologia de imagem e a elaboração do conhecimento escolar. Esses dois momentos, preparação e apresentação, permitem a todos nós, organizadores e participantes, uma reflexão acerca do tra- balho que estamos realizando - ou o que pretendemos realizar -, visto que estamos focando nosso interesse no planejamento, nas formas e possibilidades de utilização de recursos tecnológicos, nos procedimentos e práticas pedagógicas, na avaliação, questões de extrema relevância na construção do conhecimento.

Mesmo o Projeto estando inserido em uma área específica - o Desenho - nosso objetivo é reunir docentes de todas as áreas do conhecimento. Portanto, esse é um Seminário criado para e pelo docente - de qualquer que seja a área em que esteja inserido - da Educação Básica: para que ele possa colher informações, atualizar seus conhecimentos; pela contribuição trazida por ele compartilhando suas idéias, suas expectativas e também suas inquietações.

Muitas destas inquietações geram demandas, algumas delas já identificadas em pesquisa de campo realizada pelo Projeto LEDEN e que, aliás, nos forneceram os subsídios para a estruturação do Seminário, apontando, inclusive, a necessidade da participação de profissionais de áreas afins como a lingüística, a comunicação, a informática, entre outras.

\section{Comunicação Visual e Formação DOCENTE (E DISCENTE) - A FALA DO PROFESSOR}

A atual estruturação do ensino escolar no que diz respeito à linguagem visual - 0 suporte da imagem - não atende às necessidades da sociedade contemporânea. Vivemos em um mundo absolutamente imagético e, no entanto, continuamos a fazer uso dessas imagens de forma intuitiva. Isto revela a distância que separa a escola do mundo, no qual a sociedade lida com a imagem em termos de manipulação, conserva- 
e-Mosaicos - Revista Multidisciplinar de Ensino, Pesquisa, Extensão e Cultura do Instituto de Aplicação Fernando Rodrigues da Silveira (CAp-UERJ)

ANO 1 - V. 1 - N. 1 - JUNHO 2012 - ISSN: 2316-9303

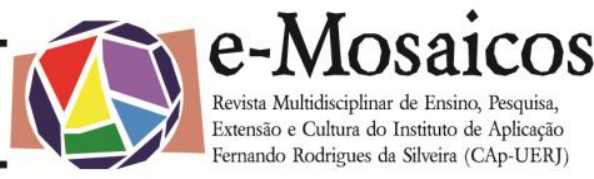

ção e consumo.

Não há praticamente investigação teórica ou pesquisas, inseridas no contexto acadêmico, referentes ao trabalho com a linguagem visual voltado para as formações docente e discente. Apesar da existência de muitos projetos que tratam a imagem a partir da Semiótica e de outras teorias da Lingüística, da Gestalt e de outras teorias da Comunicação e da Informação, não temos notícia de que algum deles tenha seus objetivos voltados para a construção do conhecimento escolar básico em nível transdisciplinar, o que levaria necessariamente a uma reflexão sobre a mudança de perspectiva nas propostas curriculares, tanto para a Educação Básica como para a formação docente de nível superior.

Essas constatações nos levam a algumas perguntas, para as quais não temos respostas: por que as Diretrizes Curriculares e os Parâmetros Curriculares Nacional PCNs - não tratam dessa questão? Rebatizar a disciplina Artes Plásticas como Artes Visuais realmente mudou o objeto e a forma pela qual ela é estudada? Por que a academia não se ocupa dessas questões? Por que a escola também não se interessa? Tudo isso se resume a uma só questão: a das políticas públicas?

Essas indagações permanecem em nossas reflexões. Mas uma simples pergunta, cuja resposta foi possível obter, deu origem à pesquisa de campo já mencionada, do Projeto LEDEN: O que está acontecendo no cotidiano escolar da Educação Básica? Evidentemente estamos pensando no trabalho com a Linguagem Visual.

É possível perceber que existem associações estabelecidas, poderíamos dizer imediatas e sem qualquer fundamentação - praticamente cristalizadas - que são verbalizadas da seguinte maneira: ou o aluno é bom em artes visuais ou em outras áreas do conhecimento. $\mathrm{O}$ trabalho com a imagem é visto como uma questão de talento, de curiosidade, de interesse, de dom; como se a linguagem visual não necessitasse de qualquer bagagem intelectual e de conhecimento do mundo para ser desenvolvida.

Essa postura produz uma visão equivocada do processo de aprendizagem que pode - e deveria - ser vivenciado de formas diferenciadas, de acordo com os sujeitos nele inseridos. Muitos desses sujeitos têm a descoberta de conceitos facilitada através de relações que conseguem estabelecer a partir de imagens; não havendo ambiente favorável para tal experimentação, o caminho tomado é o da palavra, da abstração, que muitas vezes leva ao fracasso escolar.

Partindo deste princípio, realizamos uma pesquisa, de caráter quanti-qualitativo, com professores da Rede Pública de Educação Básica do Estado do Rio de Janeiro, atuantes na capital e no interior, para definição do perfil desse docente, ou seja, do tipo de acesso aos recursos de formação e de material relativos à linguagem visual, de procedimentos utilizados ou não e de seu pensamento a respeito dessa área de conhecimento.

Um questionário foi elaborado, cujas respostas foram tabuladas, quantificadas $\mathrm{e}$ expressas em gráficos. Entrevistas foram realizadas, o que permitiu, criar categorias, também expressas através de gráficos. Analisando esse material, chegamos a algumas constatações exemplificadas com as perguntas e os gráficos correspondentes. 
- $\quad$ Existe uma significativa falta de formação e informação na área de Linguagem Visual. Os professores não participam de cursos nessa área, mas acreditam na melhoria proporcionada pela realização destes em sua atuação profissional

Pergunta: Você sente falta de formação ou informação na área de Linguagem Visual para entender melhor o funcionamento das imagens e sua utilização de forma mais produtiva?

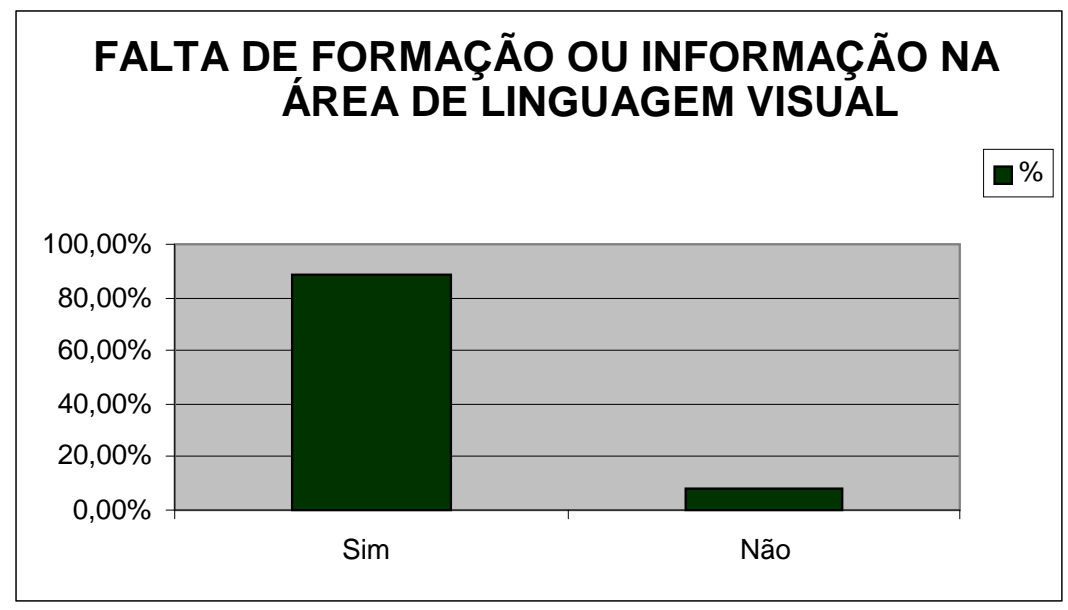

Pergunta: Você acha que um curso nesta área poderia lhe ajudar em sua formação profissional?

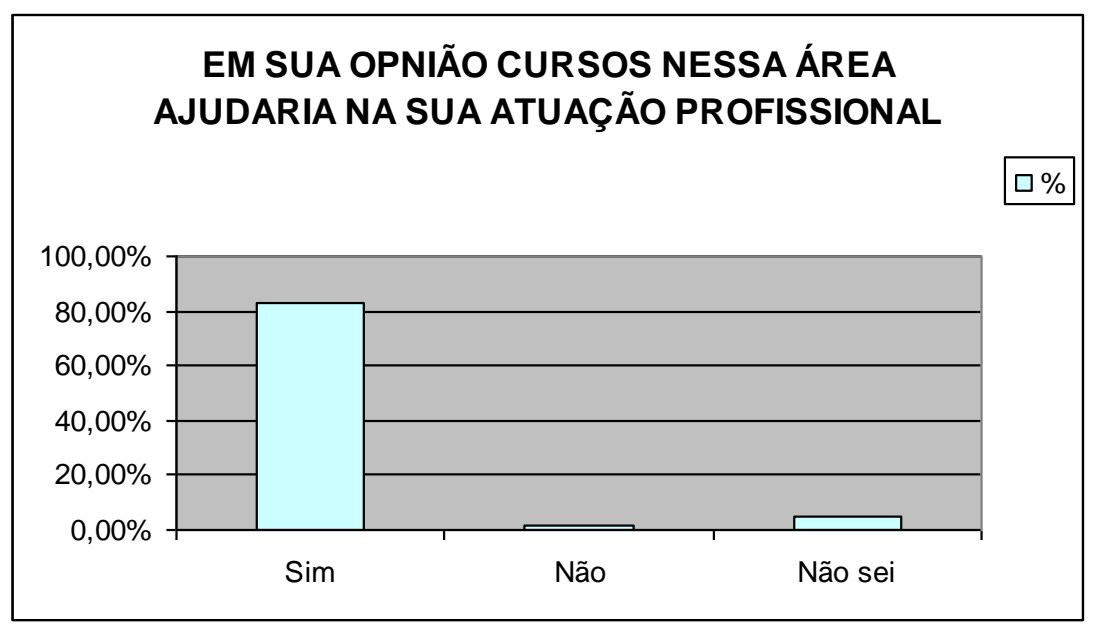

- Muitos professores utilizam imagens em suas aulas, mas a maioria delas tratadas por outros meios e não pelas novas tecnologias, mesmo tendo acesso a estas na escola ou através de recursos próprios. 
Pergunta: No caso de imagens fixas, estas imagens são tratadas de alguma forma?

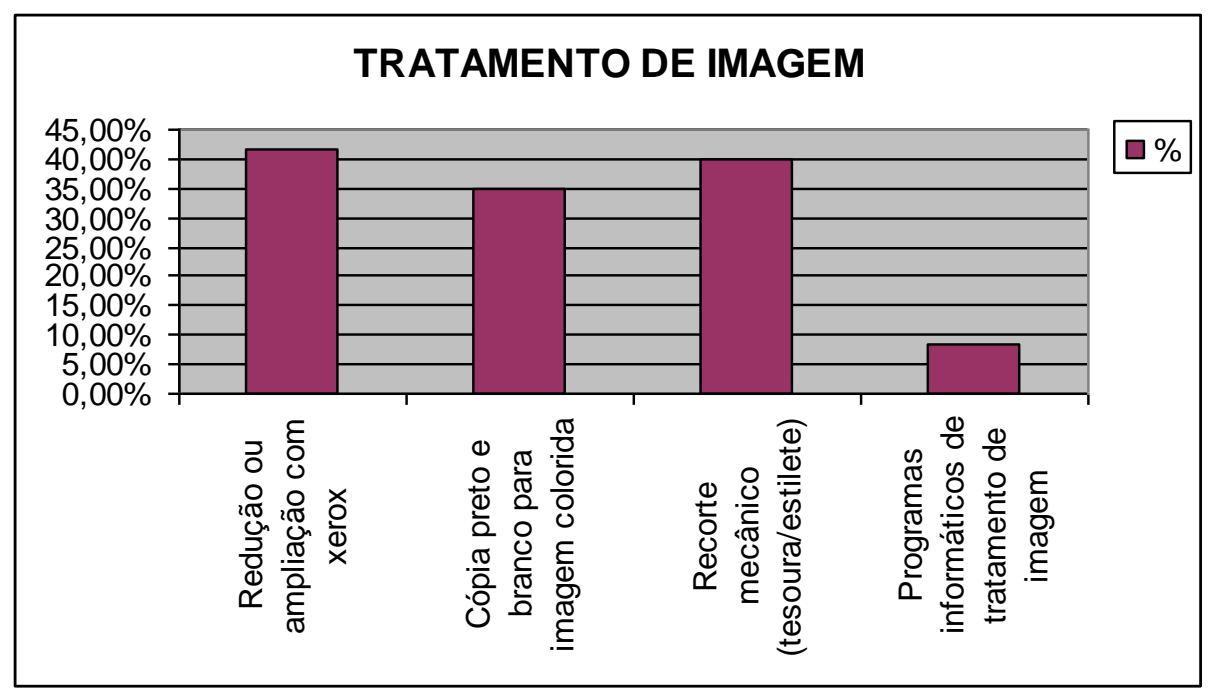

Pergunta: Você tem acesso aos seguintes recursos?

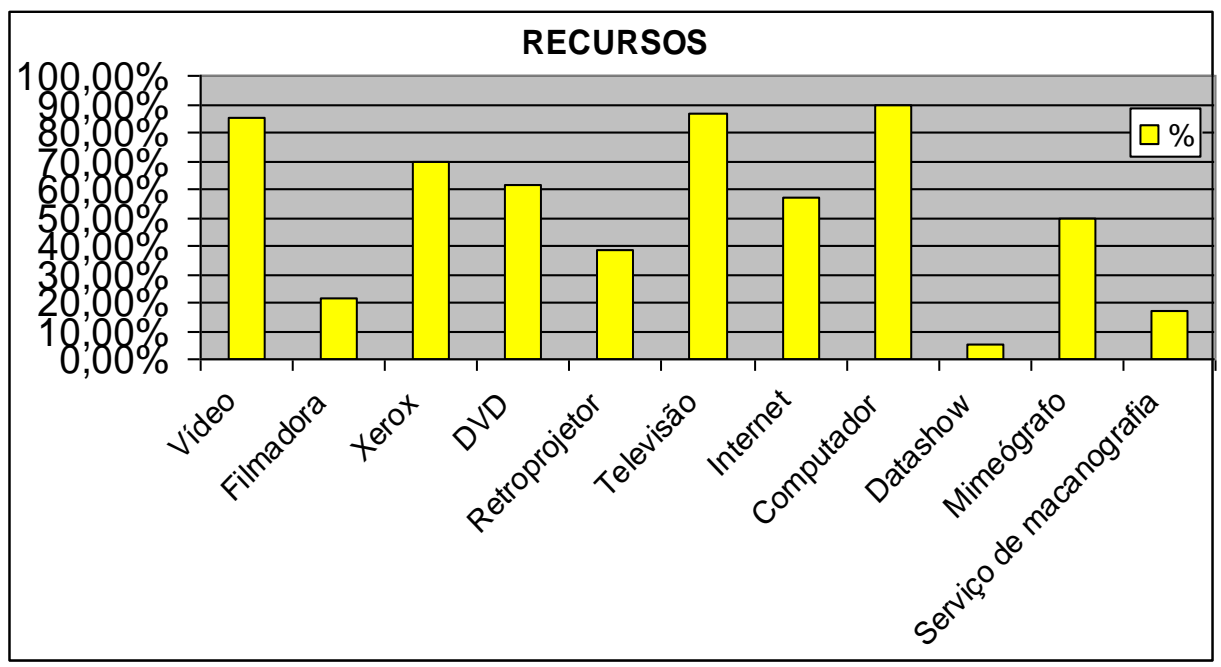

- A maior dificuldade apontada pelos professores foi a de avaliar a adequação da imagem aos objetivos de suas aulas, o que se confirmou na quantidade de demandas de curso para esse fim. 
e-Mosaicos - Revista Multidisciplinar de Ensino, Pesquisa, Extensão e Cultura do Instituto de Aplicação Fernando Rodrigues da Silveira (CAp-UERJ) ANO 1 - V. 1 - N. 1 - JUNHO 2012 - ISSN: 2316-9303

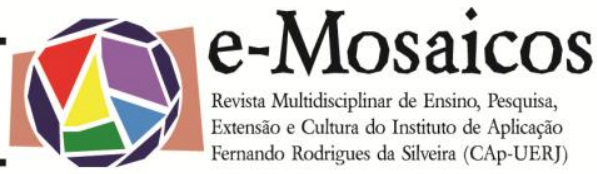

Pergunta: 0 que você esperaria aprender sobre imagens/linguagem visual para aprimorar seu trabalho em sala de aula e sua formação profissional?

\begin{tabular}{|l|c|}
\hline \multicolumn{1}{|c|}{$\begin{array}{c}\text { TODAS AS PROPOSTAS } \\
\text { SUGERIDAS }\end{array}$} & $\%$ \\
\hline $\begin{array}{l}\text { Avaliar a adequação da imagem } \\
\text { aos objetivos de sua utilização }\end{array}$ & 20,00 \\
\hline $\begin{array}{l}\text { Criar intimidade com os instrumen- } \\
\text { tos }\end{array}$ & 1,70 \\
\hline Produção de imagens & 1,70 \\
\hline Como utilizar recursos da Internet & 1,70 \\
\hline Como usar recursos dos programas & 1,70 \\
\hline Aprender sobre a linguagem visual & 5,00 \\
\hline Tratamento da imagem & 1,70 \\
\hline Fotografia & 1,70 \\
\hline Desenho & 6,70 \\
\hline $\begin{array}{l}\text { Técnicas para utilizar e aplicar es- } \\
\text { ses recursos }\end{array}$ & 5,00 \\
\hline Modificar e recuperar imagens & 10,00 \\
\hline Escolha da imagem & 5,00 \\
\hline Datashow & 1,70 \\
\hline Imagem no espaço & 1,70 \\
\hline Criação de murais & 1,70 \\
\hline Aquisição de imagens & 5,00 \\
\hline Audiovisual & 1,70 \\
\hline $\begin{array}{l}\text { Como trabalhar com imagem nas } \\
\text { disciplinas }\end{array}$ & 1,70 \\
\hline Reprodução de imagens & 1,70 \\
\hline $\begin{array}{l}\text { Trabalhar os significados, as inter- } \\
\text { pretações e a própria construção } \\
\text { da imagem }\end{array}$ & 6,70 \\
\hline
\end{tabular}

Em síntese, o que o professor manifesta é a crença na utilização da imagem como promotora de aprendizagem e uma real necessidade de capacitação para o trabalho com essa linguagem, trabalho este diferente do que tem sido feito na escola básica, na medida em que o sentido da linguagem visual está associado às artes visuais.

Pretendemos com os desdobramentos desta pesquisa que o conceito de Linguagem Visual ganhe uma nova amplitude e envolva todos os contextos imagéticos do espaço escolar; tanto os de captura e tratamento de imagens, quanto os de geração e leitura, estudos culturais e processos de significação. Isso justificaria discussões sobre propostas curriculares em nível de escolarização básica e de formação docente.

\section{CONSIDERAÇões Finais}

Este projeto tem como proposta um espaço na educação brasileira para o ensino da Linguagem Visual, tanto no ensino básico como na formação docente. A primeira proposta é mais ampla e demorada e implica o aprofundamento da discussão sobre questões curriculares. A segunda é mais urgente, pois existem recursos disponíveis na área de Linguagem Visual que não podem mais ser ignorados nos processos de aprendizagem, posto que contribuem na redução do fracasso escolar.

Os sujeitos envolvidos neste projeto de pesquisa acreditam na necessidade premente de se oferecer ao docente de Educação Básica e àqueles que estão em formação acesso ao campo da Linguagem Visual com suas implicações teóricas e práticas. Se 0 professor precisa e não há oferta, nem por parte da Universidade nem da Rede Pública, é nosso papel não assumir essa responsabilidade, mas propor alternativas tais como: 
e-Mosaicos - Revista Multidisciplinar de Ensino, Pesquisa, Extensão e Cultura do Instituto de Aplicação Fernando Rodrigues da Silveira (CAp-UERJ) ANO 1 - V. 1 - N. 1 - JUNHO 2012 - ISSN: 2316-9303

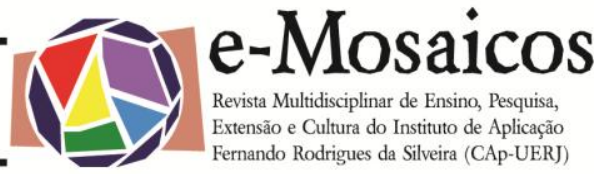

formação de grupos de estudo, cursos de extensão, de formação continuada, atualizaç̃os, eventos, visto que só através dessa parceria será possível caminhar tendo como objetivo maior a melhoria da qualidade do ensino.

\section{REFERÊNCIAS BIBLIOGRÁFICAS:}

ALMEIDA, Milton José. Imagens e Sons: a nova cultura oral. Coleção: questões da nossa época: vol. 32. São Paulo: Cortez, 1994.

ARAGÃO, Teresa Maria da F. M. Arte Educação: Um Desafio de Muitas Faces. Dissertação de Mestrado. Rio de Janeiro: Fundação Getulio Vargas, 1994.

BARTHES, Roland. 0 óbvio e o obtuso. Rio de Janeiro: Nova Fronteira, 1990.

CERTEAU, Michel de. A Invenção do Cotidiano. 1. Artes de Fazer. Petrópolis: Vozes, 2003.

CHALHUB, Samira. Funções da Linguagem. São Paulo: Editora Atica, 2001.

CHEVALIER, Jean. Dicionário de Símbolos: (mitos, sonhos, costumes, gestos, formas, figuras, cores e números). Rio de Janeiro: José Olympio, 2003.

DERDYK, Edith. Formas de pensar o desenho. São Paulo. Editora Scipione, 1994.

DONDIS, Donis A Sintaxe da Linguagem Visual. São Paulo: Editora Martins Fontes, 1999.

FERRARA, Lucrecia D'Aléssio. Leitura sem palavras. 4ed. São Paulo: Ática. 1986.

JOLY, Martine. Introdução a Análise da Imagem. Campinas. Editora Papirus, 1996.

LURIA, A. R. Pensamento e Linguagem: as últimas conferências de Luria. Porto Alegre: Arte Médicas, 1987.
OLIVEIRA. Inês Barbosa de. Currículos Praticados: entre a regulação e a emancipação. Rio de Janeiro: DP\&A, 2003.

SANTOS, Boaventura de Sousa. A crítica da Razão indolente. Contra o desperdício da experiência. São Paulo: Cortez, 2000.

THUILLIER, P. De Arquimedes a Eisntein A Face Oculta da Invenção Científica Rio de Janeiro: Jorge Zahar, 1994.

ULBRICHT, Sergio Murilo. Geometria de Desenho: história, pesquisa e evolução. Florianópolis: 1998.

WONG, Wucius. Princípios da Forma e do Desenho. São Paulo: Martins Fontes, 2001.

ZELADA, Gian. Narrativa Visual: arte e ciência unidas para representar um mundo novo in: Anais do $15^{\circ}$ Simpósio de Geometria Descritiva e Desenho Técnico / IV International Conference on Gragphics Engineering for Arts and Design. São Paulo, 2001.

${ }^{1}$ esequiel@uerj.br - possui Graduação em Educação Artística pela Universidade Federal do Rio de Janeiro (1985), Mestrado em Educação pela Universidade do Estado do Rio de Janeiro (2001) e Doutorado em Educação pela mesma Instituição (2006). Atualmente, é professor adjunto da UERJ / Instituto de Aplicação Fernando Rodrigues da Silveira - CAp-UERJ. Tem experiência na área de Educação, com ênfase em Métodos e Técnicas de Ensino, atuando principalmente nos seguintes temas: linguagem visual, leitura de imagem, educação básica, educação artística, ensino de desenho e formação de professores.

2 igdavid@uol.com.br - Graduada em Matemática pela Universidade Federal do Rio de Janeiro (1985). Professora Auxiliar da Universidade do Estado do Rio de Janeiro / Instituto de Aplicação Fernando Rodrigues da Silveira - CAp-UERJ desde 1985. Desenvolve pesquisas relacionadas a 
atividades de sala de aula (propostas curriculares, atividades pedagógicas, elaboração de material concreto e jogos etc). Faz parte do Grupo de Pesquisa do Projeto Matemática Viva. Atualmente vem trabalhando nos anos iniciais do segundo segmento do Ensino Fundamental.

3 mariarmf@ig.com.br - Graduada em Letras / Português-Francês pela Universidade Federal Fluminense, Mestrado em Letras pela Universidade Federal Fluminense e Doutorado em Letras pela Universidade Federal Fluminense. Atualmente é Professora Adjunta da Universidade do Estado do Rio de Janeiro / Instituto de Aplicação Fernando Rodrigues da Silveira - CAp-UERJ, membro de grupo de pesquisa CNPq da Universidade Federal Fluminense e professora da Aliança Francesa. Tem experiência na área de Letras, com ênfase em Francês Língua Estrangeira, atuando principalmente nos seguintes temas: francês, língua estrangeira, teoria da literatura, leitura e modernidade.

${ }^{4}$ soraya.barcellos@terra.com.br - Licenciada em Educação Artística, hab. Desenho pela Escola de Belas Artes da Universidade Federal do Rio de Janeiro (1989), Especialização em Técnicas de Representação Gráficas pela Escola de Belas Artes da Universidade Federal do Rio de Janeiro (2004) e em Metodologia e Didática do Ensino Superior pela Universidade Estácio de Sá (1995). Atualmente é Professora Auxiliar da Universidade do Estado do Rio de Janeiro/ Instituto de Aplicação Fernando Rodrigues da Silveira - CAp-UERJ, Professora do Colégio Pedro II e Tutora Acadêmico-Administrativa da UAB/UFF/CEDERJ do Curso de Especialização Lato Senso à Distância em Novas Tecnologias no Ensino de Matemática. Foi Professora Substituta de Geometria Descritiva I na FAU/UFRJ (2005/2006) e do IME/UERJ (2004/1). Tem experiência na área de Educação, Educação Superior e Básica, Educação a Distância, atuando principalmente nos seguintes temas: novas tecnologias, linguagem visual, desenho, web design, metodologia e construção do conhecimento. 